\title{
Analisis On-Bottom Stability dan Local Buckling: Studi Kasus Pipa Bawah Laut dari Platform Ula Menuju Platform Uw
}

\author{
Clinton Sibuea, Yeyes Mulyadi, dan Imam Rochani \\ Jurusan Teknik Kelautan, Fakultas Teknologi Kelautan, Institut Teknologi Sepuluh Nopember (ITS) \\ Jl. Arief Rahman Hakim, Surabaya 60111 Indonesia \\ e-mail: yeyesmulyadi@gmail.com
}

\begin{abstract}
Abstrak-Pipa bawah laut merupakan suatu teknologi transportasi yang digunakan untuk mengangkut produk hidrokarbon. Industri minyak dan gas telah membuktikan bahwa penggunakan pipa bawah laut merupakan cara yang paling ekonomis untuk memindahkan fluida dalam skala besar. Pada penelitian ini, dilakukan analisis on-bottom stability dan local buckling pada pipa bawah laut dari platform ULA menuju platform UW milik PT.PHE ONWJ. Analisis on-bottom stability bertujuan untuk mengetahui apakah pipa bawah laut stabil secara vertikal dan lateral di dasar laut pada saat terkena beban hidrodinamis. Analisis local buckling bertujuan untuk menentukan panjang maksimum free span yang diijinkan agar pipa tidak mengalami buckling. Besar gaya horizontal pada kondisi instalasi dan operasi masing-masing adalah $405 \mathrm{~N} / \mathrm{m}$ dan $1119 \mathrm{~N} / \mathrm{m}$. Besar gaya vertikal pada kondisi instalasi dan operasi masing-masing adalah $138 \mathrm{~N} / \mathrm{m}$ dan $1058 \mathrm{~N} / \mathrm{m}$. Besar gaya tahanan tanah pada kondisi instalasi dan operasi masing-masing adalah $111 \mathrm{~N} / \mathrm{m}$ dan $121 \mathrm{~N} / \mathrm{m}$. Hasil analisis absolute lateral static menunjukkan pipa bawah laut tidak stabil secara lateral pada kondisi instalasi dan operasi karena berat terendam aktual lebih kecil dari berat terendam minimum yang harus dipenuhi agar stabil. Hasil analisis generalized parameter menunjukkan pipa bawah laut tidak stabil secara lateral pada kondisi operasi, namun stabil secara lateral pada kondisi instalasi. Panjang free span pipa bawah laut maksimum yang diijinkan agar tidak terjadi local buckling adalah $50 \mathrm{~m}$.
\end{abstract}

Kata Kunci-Pipeline, On-Bottom Stability, Local Buckling.

\section{PENDAHULUAN}

$\mathrm{P}$ T. Pertamina Hulu Energi Offshore North West Java (PHE ONWJ) adalah anak perusahaan PT. Pertamina Hulu Energi. Perusahaan ini menyelenggarakan usaha hulu di bidang minyak dan gas bumi. Wilayah kerja PHE ONWJ mencakup area sekitar 8.300 kilometer persegi di Laut Jawa yang terletak di utara Kepulauan Seribu sampai perairan utara Cirebon. Hingga Juni 2015, PHE ONWJ berhasil mencapai rata-rata produksi sebesar 40.400 barel minyak per hari (BOPD). Sedangkan produksi gas bumi PHE ONWJ mencapai 173 MMSCFD. Produksi minyak dan gas bumi PHE ONWJ disalurkan seluruhnya untuk kebutuhan strategis nasional seperti BBM, pembangkit listrik dan bahan baku pembuatan pupuk.

Wilayah kerja yang terletak di laut lepas membuat perusahaan memerlukan banyak teknologi canggih untuk menjalankan kegiatan operasi hulu minyak dan gas. Fasilitas yang dimiliki PHE ONWJ terdiri dari lebih dari 200 struktur platform, 404 jaringan pipa bawah laut sepanjang 1900 kilometer.

Pipa bawah laut merupakan suatu teknologi transportasi yang digunakan untuk mengangkut produk hidrokarbon seperti minyak mentah, gas alam bertekanan tinggi, dan kondensat yang relative rendah. Fluida yang dibawa pipa bawah laut dalam jumlah besar dan jarak yang jauh dilewatkan melalui jalur laut atau lepas pantai. Pipa bawah laut dapat bekerja 24 jam sehari, 265 hari dalam setahun selama umur pipa yang bisa mencapai 30 tahun atau bahkan lebih [1].

Industri minyak dan gas telah membuktikan bahwa penggunakan pipa bawah laut merupakan cara yang paling ekonomis untuk memindahkan fluida dalam skala besar. Hal tersebut dikarenakan operasi penyaluran fluida dengan pipa bawah laut bersifat kontiniu dan handal. Pipa bawah laut telah menunjukkan kemampuan untuk bertahan pada berbagai macam kondisi lingkungan yang buruk [2]. Namun, jika pipa bawah laut mengalami kegagalan akan menimbulkan kerugian ekonomi dan lingkungan yang sangat besar, sehingga perancangannya memerlukan banyak analisis [3].

Analisis on-bottom stability merupakan salah satu analisis utama pada perancangan pipa bawah laut. Analisis on-bottom stability bertujuan untuk menentukan berat minimum pipa agar dapat stabil di dasar laut [4]. Pipa bawah laut dikatakan stabil apabila gaya tahanan tanah lebih besar daripada gaya akibat beban hidronamis yang bekerja pada pipa [5].

Saat ini, DnV RP F109 adalah code yang sering digunakan untuk analisis stabilitas pipa bawah laut. Sehingga, pada penelitian ini dilakukan analisa stabilitas pipa bawah laut dari platform ULA ke UW sepanjang 3,8 mil dengan menggunakan DnV RP F109 revisi tahun 2010.

Pada kondisi operasional pipa bawah laut, sering terjadi scouring tanah di bawah pipa yang menyebabkan free span pada pipa bawah laut. Sehingga perlu juga dilakukan analisis local buckling pada free span pipa bawah laut.

\section{DASAR TEORI}

\section{A. On-Bottom Stability}

Analisis on-bottom stability dilakukan untuk mengetahui stabilitas pipa ketika terkena gaya gelombang dan arus. Ada 
tiga jenis stabilitas yang dianalisis pada analisis on-bottom stability pada penelitian ini, yaitu:

1) Stabilitas Vertikal

Untuk menghindari pipa mengapung, berat terendam pipa harus memenuhi kriteria berikut [6]:

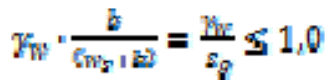

Keterangan:

$\gamma_{w}:$ Safety factor

$b$ : Gaya apung pipa

$w_{s}:$ Berat terendam pipa

$S_{g}$ : Pipe specific gravity

2) Absolute Lateral Static Stability

Metode Absolute Lateral Static Stability memberikan tidak mengijinkan perpindahan lateral pipa didasar laut berdasarkan penyamaan gaya yang memastikan gaya tahanan pipa mencukupi untuk bertahan terhadap beban hidrodinamis maksimum.

Pada metode ini, koefisien lift, drag, dan inersia digantikan dengan koefisien beban vertikal dan horizontal. Koefisien didapatkan berdasarkan data eksperimen [6].

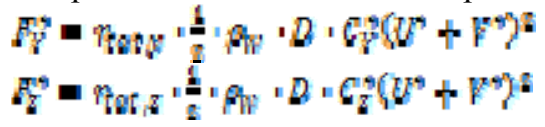

Keterangan:

$F_{Y}^{*}$ : Beban horizontal

$F_{z}^{*} \quad$ : Beban vertikal

$\mathrm{r}_{\text {tot }}$ : Faktor reduksi beban

$P_{2 y}$ : Massa jenis air laut

$\mathrm{D}:$ Diameter pipa

$C_{Y}^{*}:$ Koefisien reduksi beban horizontal

$C_{z}^{*}$ : Koefisien reduksi beban vertikal

Desain kriteria metode absolute stablity adalah [6]:

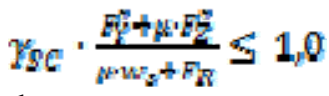

dan

$\chi_{S e} \cdot \frac{E_{2}}{w_{g}} \leq 1,0$

Keterangan:

$\gamma_{\mathrm{SC}}:$ Faktor keamanan

$F_{Y}^{*}:$ : Beban horizontal

$F_{z}^{*} \quad$ : Beban vertikal

$\mathrm{W}_{\mathrm{s}}:$ : Berat terendam pipa

$\mathrm{F}_{\mathrm{R}}$ : Gaya tahanan pasif tanah

3) Generalized Lateral Stability

Generalized lateral stability mengiiinkan perpindahan lateral sebesar $1 / 2$ sampai 10 kali diameter pipa. Berat minimum yang diperlukan agar pipa berpindah maksimal sejauh $1 / 2$ kali diameter pipa pada tanah lempung dapat dihitung dengan rumus beriku [6]:

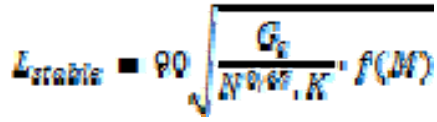

dimana,

$$
f M T=\left[0,390 \log M+0,60 \cdot 909 M^{2}+0,47\right]^{4 / 4} \leq 10
$$

Gc : Soil (clay) strength parameter

M : Rasio kecepatan arus dan gelombang

$\mathrm{K} \quad$ : Keulegan-carpenter number

$\mathrm{N} \quad$ : Faktor percepatan spektra

Untuk perpindahan pipa maksimal sejauh 10 kali diameter, berat minimum yang diperlukan dapat dihitung dengan rumus berikut [6]:

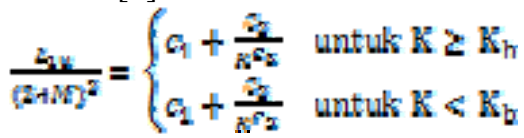

Keterangan:

M : Rasio kecepatan arus dan gelombang

$\mathrm{K} \quad$ : Keulegan-carpenter number

$\mathrm{K}_{\mathrm{b}} \quad$ : Equivalent soil roughness parameter

$\mathrm{c}_{1}, \mathrm{c}_{2}, \mathrm{c}_{3} \quad$ : Koefisien berat minimum

\section{B. Local Buckling}

Local buckling adalah deformasi plastis pada sebagian kecil dari panjang pipa yang menyebabkan perubahan besar pada penampang pipa. Local buckling disebabkan oleh kombinasi tekanan eksternal, tekanan internal, gaya aksial, dan bending moment.

Member pipa yang mengalami bending moment, effective axial force dan internal overpressure harus didesain agar memenuhi kriteria berikut ini pada semua bagian [7]:

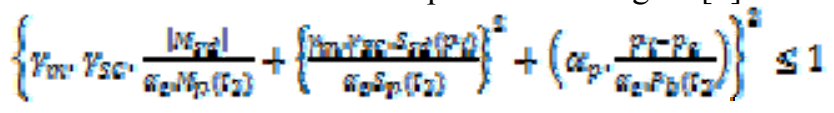

dimana,

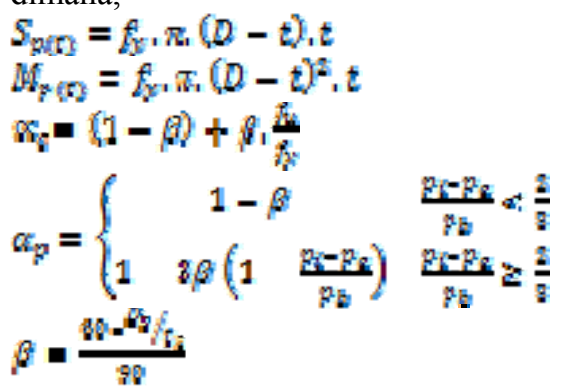

Keterangan:

$S_{p}:$ Kapasitas plastis aksial pipa

$M_{g}$ : Kapasitas plastis momen pipa

$M_{\mathrm{S}}$ : Design moment

$S_{\text {sd }}:$ Design effective axial force

$p_{i}$ : Tekanan internal

$p_{s}:$ : Tekanan eksternal

$p_{b}$ : Burst pressure

$\mathrm{f}_{\mathrm{y}} \quad$ : Yield strength

$f_{u} \quad$ : Ultimate strength

D : Diameter pipa

$\mathrm{T}$ : Tebal pipa

$\gamma_{\mathrm{m}}$ : Material resistance factor

$\gamma_{s e}:$ Safety class resistance factor

$\alpha_{c} \quad$ :Flow stress parameter

$\alpha_{p}:$ Faktor tekanan

B : Faktor pada kombinasi beban

Keterangan: 


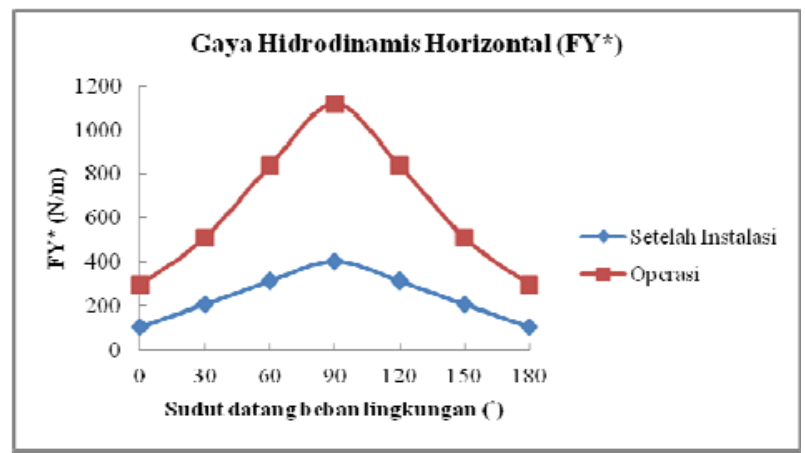

Gambar 4.1: Grafik gaya hidrodinamis horizontal

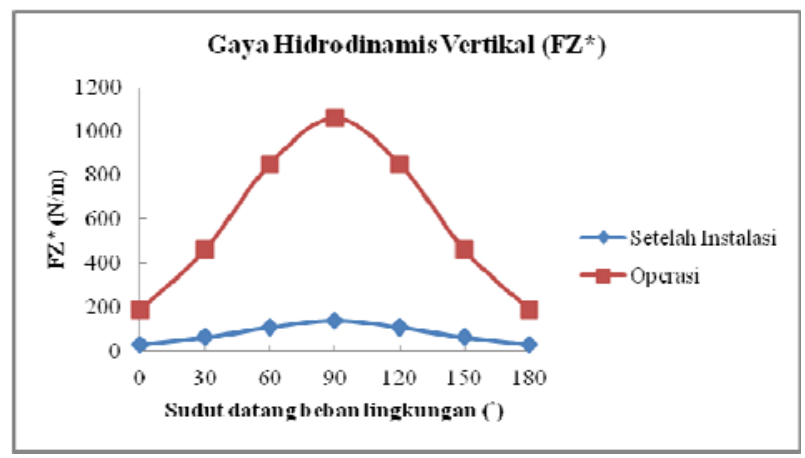

Gambar 4.2: Grafik gaya hidrodinamis vertikal

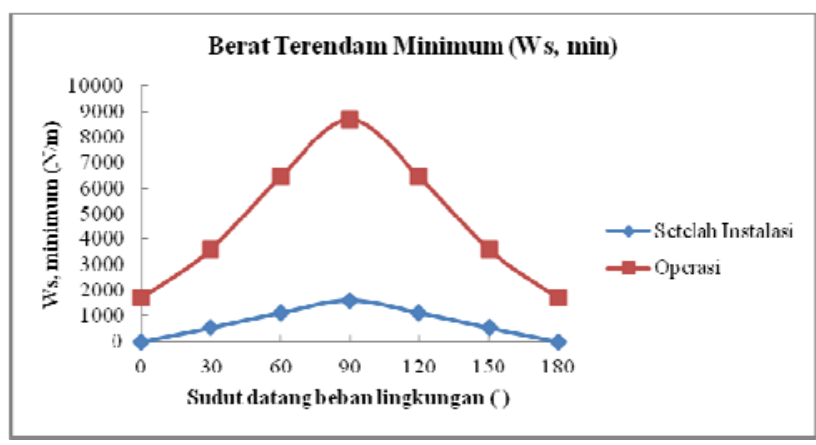

Gambar 4.3: Grafik Berat Terendam Minimum (Ws,min)

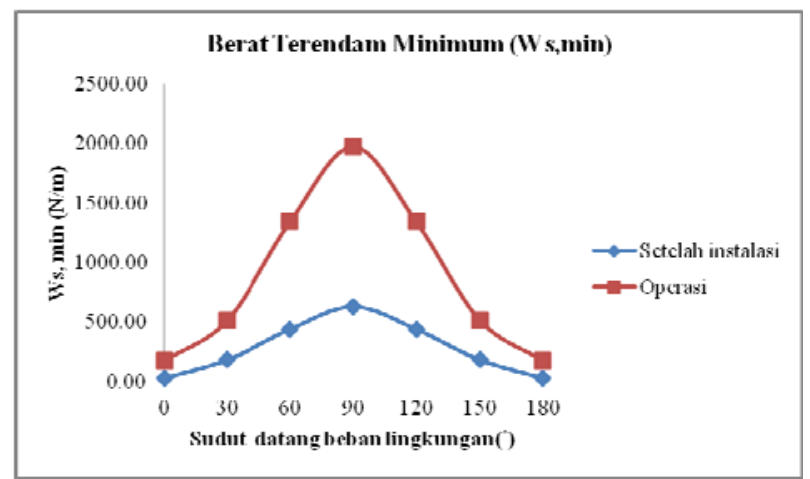

Gambar 4.4: Grafik Berat Terendam Minimum

\section{METODOLOGI}

\section{A. Studi Literatur}

Tahap ini penulis akan mempelajari serta memahami teori teori dasar tentang on-bottom stability dan local buckling pipa bawah laut dan dan penelitian yang berhubungan dengan stabilitas pipa bawah laut. Literatur berupa buku, tugas akhir, jurnal dll.

\section{B. Pengumpulan Data}

Tahap ini, penulis mengumpulkan data-data yang diperlukan dalam pengerjaan penelitian seperti data pipa, tanah, gelombang dan arus.

\section{Penentuan Kombinasi Pembebanan}

Beban yang dikombinasikan adalah gelombang dan arus. Kondisi pembebanan terbagi menjadi dua, yaitu:

Kondisi Sementara (Setelah Instalasi)

Kondisi Permanen (Operasi)

Perhitungan Kondisi Gelombang, Arus, Pipa dan Tanah

Perhitungan bertujuan untuk mendapatkan kecepatan gelombang, arus dan tahanan tanah yang bekerja pada pipa.

\section{Analisis Stabilitas Vertikal}

Perhitungan bertujuan untuk menentukan berat minimum pipa untuk memenuhi syarat stabilitas vertikal.

\section{E. Analisis Generalized Lateral Stability}

Pada perhitungan ini, perpindahan pipa yang diijinkan adalah 10 kali diameter.

\section{F. Analisis Absolute Static Stability}

Perhitungan bertujuan untuk mementukan berat minum pipa agar tidak berpindah saat terkena beban beban lingkungan pada kondisi setelah instalasi (kosong) dan operasi (berisi fluida).

\section{G. Analisis Local Buckling}

Analisis local buckling bertujuan untuk mencari panjang span maksimum agar tidak terjadi buckling pada pipa.

\section{H. Hasil Analisis dan Pembahasan}

Hasil analisis on-bottom stability dan local buckling pada free span akan disajikan dalam bentuk tabel dan grafik serta dilakukan pembahasan terhadap hasil analisis yang didapat.

\section{Kesimpulan}

Pengambilan kesimpulan sesuai dengan permasalahan yang diangkat pada penelitian ini.

\section{ANALISA DATA DAN PEMBAHASAN}

\section{A. Analisis Gaya Hidrodinamis}

Koefisien gaya drag, gaya angkat, dan gaya inersia pada perhitungan gaya hidrodinamis digantikan dengan koefisien beban vertikal dan horizontal berdasarkan data eksperimen laboratorium dan data lapangan.

Gambar 4.1 dan Gambar 4.2 menunjukkan beban hidrodinamis horizontal dan vertikal paling tinggi terjadi pada sudut pembebanan $90^{\circ}$ karena tidak ada reduksi beban pada sudut $90^{\circ}$.

\section{B. Analisis Tahanan Tanah}

Tahanan tanah terbagi menjadi dua, yaitu Coulomb friction 
Tabel 4.1: Gaya tahanan tanah

\begin{tabular}{|l|c|c|}
\hline \multirow{2}{*}{ Tahanan tanah } & Setelah Instalasi & Operasi \\
\cline { 2 - 3 } & $(\mathrm{N} / \mathrm{m})$ & $(\mathrm{N} / \mathrm{m})$ \\
\hline Coulomb friction & 184 & 202 \\
\hline Tahanan pasif & 111 & 121 \\
\hline
\end{tabular}

Tabel 4.2: Hasil analisis stabilitas vertikal

\begin{tabular}{|l|c|c|}
\hline \multicolumn{1}{|c|}{ Kondisi } & Ws, $\min (\mathrm{N} / \mathrm{m})$ & Ws, aktual (N/m) \\
\hline Setelah Instalasi (Kosong) & 150 & 918 \\
\hline Operasi (berisi fluida) & 150 & 150 \\
\hline
\end{tabular}

Tabel 4.3: Hasil analisis local buckling pada free span

\begin{tabular}{|c|c|c|c|c|c|c|c|c|}
\hline $\mathrm{L}(\mathrm{m})$ & Msd (N.m) & Mp(t2) (N.m) & $\mathrm{Ssd}(\mathrm{N})$ & $\mathrm{Sp}(\mathrm{t} 2)(\mathrm{N})$ & $\mathrm{pi}(\mathrm{MPa})$ & $\mathrm{pe}(\mathrm{MPa})$ & $\mathrm{Pb}(\mathrm{t} 2)(\mathrm{MPa})$ & Local buckling check \\
\hline 40 & 221760 & 470062 & -136683 & 3812465 & 1.111 & 0.314 & 28.855 & 0.319 \\
\hline 45 & 280665 & 470062 & -136683 & 3812465 & 1.111 & 0.314 & 28.855 & 0.511 \\
\hline 50 & 346500 & 470062 & -136683 & 3812465 & 1.111 & 0.314 & 28.855 & 0.777 \\
\hline 55 & 419265 & 470062 & -136683 & 3812465 & 1.111 & 0.314 & 28.855 & 1.137 \\
\hline 60 & 498960 & 470062 & -136683 & 3812465 & 1.111 & 0.314 & 28.855 & 1.609 \\
\hline
\end{tabular}

dan tahanan pasif karena tumpukan tanah yang terbentuk akibat penetrasi pipa ke dalam tanah.

Pada kondisi setelah instalasi (kosong), Coulomb friction dan tahanan pasif masing-masing bernilai $184 \mathrm{~N} / \mathrm{m}$ dan 111 $\mathrm{N} / \mathrm{m}$. . Pada kondisi operasi (berisi fluida), Coulomb friction dan tahanan pasif masing-masing bernilai $202 \mathrm{~N} / \mathrm{m}$ dan 121 $\mathrm{N} / \mathrm{m}$. Tahanan tanah pada kondisi operasi lebih besar daripada kondisi instalasi karena pada kondisi operasi pipa terisi oleh hidrokarbon yang membuat pipa semakin berat, sehingga tahanan tanahnya juga lebih besar.

\section{Analisis Stabilitas Vertikal}

Setelah dilakukan perhitungan, didapatkan berat minimum pipa yang harus dipenuhi agar stabil secara vertikal adalah $150 \mathrm{~N} / \mathrm{m}$. Sedangkan, berat terendam aktual pipa pada saat kondisi instalasi dan operasi masing-masing adalah $918 \mathrm{~N} / \mathrm{m}$ dan $1008 \mathrm{~N} / \mathrm{m}$. Sehingga, pipa stabil secara vertikal pada kondisi instalasi dan operasi.

\section{Analisis Absolute Lateral Static Stability}

Pada kondisi instalasi, pipa masih dalam kondisi kosong atau tidak terisi fluida. Berdasarkan DnV RP F109 kombinasi pembebanan lingkungan pada kondisi operasi kombinasi pembebanan lingkungan menggunakan periode ulang 1 tahun gelombang dikombinasikan dengan periode ulang 10 tahun arus.

Pada kondisi operasi, pipa terisi dengan fluida (hidrokarbon), sehingga menambah berat terendam aktual pipa. Berdasarkan DnV RP F109 kombinasi pembebanan lingkungan pada kondisi operasi menggunakan periode ulang 10 tahun gelombang dikombinasikan dengan periode ulang 100 tahun arus. Perhitungan dilakukan dengan variasi sudut datang beban lingkungan yaitu $0-180 \mathrm{o}$.

Dari Gambar 4.3 didapatkan berat terendam minimum pipa agar memenuhi kriteria absolute lateral static adalah 1610 $\mathrm{N} / \mathrm{m}$ pada kondisi instalasi dan $8710 \mathrm{~N} / \mathrm{m}$ pada kondisi operasi. Hasil analisis menunjukkan bahwa pipa tidak memenuhi kriteria absolute lateral static stability pada kondisi instalasi maupun kondisi operasi karena berat terendam aktual pipa lebih kecil dari berat minimum yang harus dipenuhi untuk stabil. Sehingga, tebal concrete perlu ditambah menjadi $60 \mathrm{~mm}$ dan $190 \mathrm{~mm}$ atau dilakukan pipeline anchoring agar stabil pada kondisi setelah instalasi dan operasi.

\section{E. Analisis Generalized Lateral Stability}

Pada metode ini pipa diijinkan untuk berpindah secara lateral maksimal sejauh 10 kali diameter pipa. Tabel dan grafik berikut ini menunjukkan berat terendam minimum pipa agar memenuhi kriteria generalized parameter pada kondisi instalasi dan operasi.

Grafik di atas menunjukkan bahwa pipa tidak stabil pada kondisi operasi, namun stabil pada kondisi instalasi. Sehingga, tebal concrete perlu ditambah menjadi $70 \mathrm{~mm}$ dilakukan pipeline anchoring agar stabil pada kondisi operasi.

\section{F. Analisis Local Buckling}

Tegangan aksial yang terjadi pada pipa bawah laut adalah 12,39 $\mathrm{MPa}$, sedangkan tegangan aksial maksimum yang diijinkan adalah 311,04 MPa, sehingga tegangan aksial masih memenuhi kriteria ASD (allowable stress design). Kemudian, selama proses operasi pipa bawah laut kemungkinan akan terjadi free span akibat penggerusan tanah di bawah pipa oleh arus laut. Oleh karena itu, perlu dilakukan analisis local buckling pada free span untuk mengetahui berapa panjang free span yang diijinkan agar pipa tidak mengalami buckling. Local buckling pada free span dianalisis menggunakan kriteria load controlled condition pada DnV OS F101. Berikut ini adalah hasil analisis local buckling dengan panjang free span yang berbeda-beda:

Tabel di atas menunjukkan semakin panjang free span, maka semakin besar bending moment pada pipa karena semakin bertambahnya panjang dan massa pipa yang tidak memiliki tumpuan. Berdasarkan kriteria load controlled condition pada DnV OS F101, panjang maksimum free span yang diijinkan adalah $50 \mathrm{~m}$ karena nilai local buckling check masih di bawah 1 yang berarti pipa bawah laut tidak akan mengalami local buckling.

\section{KESIMPULAN DAN SARAN}

\section{A. Kesimpulan}

Dari hasil penelitian yang dilakukan dalam tugas akhir ini dapat diambil kesimpulan sebagai berikut :

Besar gaya hidrodinamis horizontal pada kondisi setelah instalasi (kosong) dan operasi (berisi fluida) masing-masing adalah $405 \mathrm{~N} / \mathrm{m}$ dan $1119 \mathrm{~N} / \mathrm{m}$. Besar gaya hidrodinamis vertikal pada kondisi setelah instalasi (kosong) dan operasi (berisi fluida) masing-masing adalah $138 \mathrm{~N} / \mathrm{m}$ dan $1058 \mathrm{~N} / \mathrm{m}$. Besar Coulomb friction pada kondisi setelah instalasi (kosong) dan operasi (berisi fluida) masing-masing adalah 184 $\mathrm{N} / \mathrm{m}$ dan $202 \mathrm{~N} / \mathrm{m}$. Besar tahanan pasif pada kondisi setelah instalasi (kosong) dan operasi (berisi fluida) masing-masing adalah $111 \mathrm{~N} / \mathrm{m}$ dan $121 \mathrm{~N} / \mathrm{m}$

Berdasarkan kriteria on-bottom stability DnV, pipa bawah laut stabil secara vertikal pada kondisi setelah instalasi (kosong) dan operasi (berisi fluida). Pada metode absolute 
lateral static pipa bawah laut tidak stabil secara lateral pada kondisi setelah instalasi (kosong) dan operasi (berisi fluida). Sehingga, tebal concrete perlu ditambah menjadi $60 \mathrm{~mm}$ dan $190 \mathrm{~mm}$ agar stabil pada kondisi setelah instalasi dan operasi. Pada metode generalized parameter pipa bawah laut tidak stabil secara lateral pada kondisi operasi (berisi fluida), namun stabil secara lateral pada kondisi instalasi (kosong). Sehingga, tebal concrete perlu ditambah menjadi $70 \mathrm{~mm}$ agar stabil pada kondisi operasi.

Panjang free span pipa bawah laut maksimum yang diijinkan agar tidak terjadi local buckling adalah $50 \mathrm{~m}$. Hasil analisis local buckling dapat digunakan untuk melakukan mitigasi pada free span pipa bawah laut.

\section{B. Saran}

Saran yang dapat diberikan pada penelitian ini untk penelitian lebih lanjut adalah:

Melakukan analisis biaya berdasarkan hasil analisis onbottom stability.

Melakukan analisis mitigasi apabila terdapat panjang free span yang melebihi panjang free span yang diijinkan.

\section{DAFTAR PUSTAKA}

[1] Soegiono. 2007. Pipa Laut. Surabaya : Airlangga University Press.

[2] Guo, B., Song, S,Chacko, J., dan Ghalambor, A. 2005. Offshore Pipelines. Gulf Professional Publishing, Burlington, USA.

[3] Tian, Y., Youssef, B., Cassidy, M.J. 2015. Assessment of pipeline stability in the Gulf of Mexico during hurricanes using dynamic analysis. Theoretical and Applied Mechanics Letters.

[4] Bai, Y., Bai, Q. 2005. Subsea Pipelines and Risers. Elsevier Science, USA

[5] Teh, T., Palmer, A., Bolton, M., dan Damgaard, J. 2006. Stability of Submarine Pipelines on Liquefied Seabeds. Journal of Waterway, Port, Coastal, Ocean Eng. 132: 244-251.

[6] Det norske Veritas. 2007. DNV RP F109, On-bottom stability design of submarine pipelines. Norway.

[7] Det norske Veritas. 2013. DNV OS F101, Submarine pipeline systems. Norway. 